\title{
Comparison of whole-body computed tomography vs selective radiological imaging on outcomes in major trauma patients: a meta-analysis
}

\author{
Libing Jiang ${ }^{\dagger}$, Yuefeng $\mathrm{Ma}^{\dagger}$, Shouyin Jiang ${ }^{\dagger}$, Ligang $\mathrm{Ye}^{\dagger}$, Zhongjun Zheng ${ }^{\dagger},{\text { Yongan } \mathrm{Xu}^{\dagger} \text { and Mao Zhang }}^{*}$
}

\begin{abstract}
Introduction: The purpose of this meta-analysis was to explore the value of whole-body computed tomography (WBCT) in major trauma patients (MTPs).

Methods: A comprehensive search for articles from Jan 1, 1980 to Dec 31, 2013 was conducted through PubMed, Cochrane Library database, China biology medical literature database, Web of knowledge, ProQuest, EBSCO, OvidSP, and ClinicalTrials.gov. Studies which compared whole-body $C T$ with conventional imaging protocol (X-ray of the pelvis and chest, trans-abdominal sonography, and/or selective $\mathrm{CT}$ ) in MTPs were eligible. The primary endpoint was all-cause mortality. The second endpoints included: time spent in the emergency department (ED), the duration of mechanical ventilation, ICU and hospital length of stay (LOS), the incidence of Multiple Organ Dysfunction Syndrome (MODS) /Multiple Organ Failure (MOF). Analysis was performed with Review Manager 5.2.10 and Stata 12.0.
\end{abstract}

Results: Eleven trials enrolling 26371 patients were analyzed. In MTPs, the application of WBCT was associated with lower mortality rate (pooled OR: $0.66,95 \% \mathrm{Cl}: 0.52$ to 0.85 ) and a shorter stay in the ED (weighted mean difference (WMD), $-27.58 \mathrm{~min} ; 95 \% \mathrm{Cl},-43.04$ to -12.12 ]. There was no effect of WBCT on the length of ICU stay (WMD, 0.95 days; $95 \% \mathrm{Cl}:-0.08$ to 1.98$)$ and the length of hospital stay (WMD, 0.56 days; $95 \% \mathrm{Cl}:-0.03$ to 1.15). Patients in the WBCT group had a longer duration of mechanical ventilation (WMD, 0.96 days, $95 \%$ Cl: 0.32 to 1.61) and higher incidence of MODS/MOF (OR, 1.44, 95\% Cl: 1.35-1.54; $P=0.00001)$.

Conclusions: The present meta-analysis suggests that the application of whole-body CT significantly reduces the mortality rate of MTPs and markedly reduces the time spent in the emergency department.

Keywords: Whole-body CT, Meta-analysis, Mortality, Trauma

\section{Introduction}

Trauma is the leading cause of death among people aged 1 to 45 years. In 2010, nearly 5.1 million people died from injuries [1-3]. Early diagnosis and treatment are usually the key elements to major trauma patients (MTPs) [4]. There have been studies reporting that a reduction of the diagnostic interval is associated with better prognosis [5-7]. Regarding this, recent guidelines for the management of bleeding and coagulopathy recommend that the time elapsed between injury and operation should be minimized [8]. Plain X-rays of the chest and pelvis, focused

\footnotetext{
*Correspondence: zmhz@hotmail.com

${ }^{\dagger}$ Equal contributors

Department of Emergency Medicine, Second Affiliated Hospital, School of

Medicine \& Institute of Emergency Medicine, Zhejiang University, No 88, Jiefang Rd, Hangzhou 310009, China
}

(c) 2014 Jiang et al.; licensee BioMed Central Ltd. This is an Open Access article distributed under the terms of the Creative Commons Attribution License (http://creativecommons.org/licenses/by/4.0), which permits unrestricted use, distribution, and reproduction in any medium, provided the original work is properly credited. The Creative Commons Public Domain Dedication waiver (http://creativecommons.org/publicdomain/zero/1.0/) applies to the data made available in this article, unless otherwise stated. assessment sonograph trauma (FAST), and organ-specific computed tomography $(\mathrm{CT})$ are conventional evaluation methods in the early diagnostic work-up in MTPs which is recommended by the Advanced Trauma Life Support $\left(\right.$ ATLS $\left.^{\circ}\right)$ protocol $[9,10]$. However, it often results in misdiagnosis of some potential life-threatening solid organ injuries and is time-consuming [4,11-16].

During the last decades, CT has played a pivotal role in the early evaluation of MTPs. High resolution multi-slice CT (HRCT) is more sensitive in detecting various occult injuries, especially those potentially life-threatening injuries. Also HRCT is more reliable in excluding underlying injuries [11-16]. Meanwhile, the introduction of multislice helical CT (MSCT) has significantly shortened the scanning time [17]. In some developed nations, an 
increasing number of trauma centers use whole-body CT (WBCT) (defined as a CT scan including the head, neck, chest, abdomen, pelvis, and spine) as an early evaluation tool in MTPs. Moreover, in some trauma centers, CT scanner has been located within the emergency department or trauma bay so as to reduce the time from patient's arrival to WBCT [18]. Recently, clinicians have recognized the advantages of WBCT (especially its diagnostic superiority and time gain) $[19,20]$. In addition, there are growing studies indicate that the integration of WBCT into the early assessment protocol significantly increases the probability of survival in those who are severely injured [18-23]. Huber-Wagner and colleagues reported that WBCT during trauma resuscitation is associated with a lower risk of mortality in patients regardless of their hemodynamic status $[18,19]$. Patients with unstable hemodynamics can be left in their single position to complete the WBCT [4].

Although the proportion of use of WBCT in major trauma has been increased (from 5\% in 2002 to $46 \%$ in 2010) $[24,25]$, greater radiation expose becomes one of the major concern for the public because it may induce potential adverse outcomes. For example, the risk of dying from radiation induced cancer is estimated to be $0.08 \%$ after one single WBCT in a 45-year old patient [26]. And 1.5\%$2.0 \%$ malignant tumors are associated with radiation expose in CT scan in America [27]. However, in the field of trauma, it remains inconclusive whether WBCT should be used as an initial assessment tool in MTPs. [28,29]. Two previous published meta-analysis reported that the application of immediate WBCT has no effect on mortality in MTPs [30,31]. Recently, several large-scale studies have indicated that the integration of WBCT into initial trauma management can decrease mortality in MTPs. As such, it is high time that those findings should be systematically analyzed.

\section{Methods}

The present meta-analysis was performed according to the preferred reporting items for systematic reviews and meta-analysis (PRISMA) statement [32] (Additional file 1).

\section{Search strategy}

A systematical search of literatures was performed until December 2013, using Cochrane Library database, PubMed, Web of knowledge, ProQuest, EBSCO, OvidSP, China Biology Medicine (http://www.Sinomed.ac.cn) and http:// www.clinicaltrials.gov. The following keywords and medical subject headings were used: WBCT, FBCT, TBCT, whole body CT, full body CT, total body CT, pan scan, pan CT, whole body computed tomography, MSCT, MDCT, multi-slice spiral CT, multi-detector CT, multislice spiral computed tomography, multi-detector computed tomography, trauma, wound", injur", multiple trauma, multiple injur*, severe injur", severe trauma, polytrauma, and major trauma. We also checked the reference lists of existing systematic reviews and other eligible studies to minimize potential publication bias. The detailed search strategies are available in Additional file 2 .

\section{Study selection}

We included studies that met the following criteria:

1) Patients: adult blunt MTPs (age $>16$ years, injury severity score (ISS) $>16$ ).

2) Intervention: WBCT.

3) Comparisons: studies compared WBCT with conventional diagnostic algorithm (NWBCT, including X-rays of the chest and pelvis and FAST followed by selective CT or no CT).

4) Outcomes: The primary endpoint was all-cause mortality rate. The secondary endpoints included: time spent in the emergency department (ED), the duration of mechanical ventilation, ICU and hospital length of stay (LOS), the incidence of Multiple Organ Dysfunction Syndrome (MODS)/Multiple Organ Failure (MOF).

5) Study design: Both randomized and observational studies.

\section{Data extraction and quality assessment}

Data were independently extracted by two reviewers (LB) AND LGY), using a data extraction sheet. The following data were extracted: characteristics of studies, characteristics of patients, types of intervention and outcomes. If necessary, we would contact the corresponding authors to obtain additional information.

The methodological quality of all eligible studies was assessed using the Newcastle-Ottawa Scale (NOS). (www.ohri.ca/programs/clinical_epidemiology/oxford.asp).

\section{Statistical analysis}

Odds ratios (OR) with 95\% confidence intervals (CI) were calculated for categorical variables and weighted mean differences (WMD) were calculated for continuous variables. If the published reports of clinical trials only reported the median, range and the size of the trial, we used these published parameters to estimate the mean and the variance (or standard deviation) for such trials according to the formulas described in the study by Hozo et al. [33]. Heterogeneity was tested by the $\mathrm{Chi}^{2}$ test $(\mathrm{P}<0.10$ indicated statistically significant heterogeneity) and $\mathrm{I}^{2}$ statistic $\left(\mathrm{I}^{2}\right.$ value $>50 \%$ indicated significant heterogeneity). The random-effect model was used when there was significant heterogeneity $\left(\mathrm{I}^{2}\right.$ value $\left.>50 \%\right)$; otherwise the fixed random-effect was used [34]. A 2sided $\mathrm{P}$ value $<0.05$ was considered statistically significant. 
Sensitivity analysis was performed for the primary endpoint (mortality). Publication bias was quantitatively detected by Egger's test [35]. The absence of publication bias is indicated by $\mathrm{P}$ value $>0.10$ in Egger's test. All statistical analyses were performed using STATA 12.0 software (SERIAL NO.40120519635) and RevMan 5.2.10 (http:// tech.cochrane.org/revman/download).

The quality of evidence in this meta-analysis was assessed using the GRADE Guidelines [36,37]. The quality of evidence is classified into four levels: high, moderate, low, and very low, according to the robustness of the evidence $[36,37]$. This process was performed using GRADE pro 3.6 software (http://www.Gradeworkinggroup.org/ toolbox/index.htm).

\section{Results}

Search results

We obtained 11116 titles and abstracts through literature search. After screening for abstracts, 11100 duplicated and non-relevant studies were excluded. And the remaining 16 studies were fully read. Of these, 5 studies were excluded and the corresponding reasons were listed in the flow chart (Figure 1). Finally, 11 studies were included in quantitative synthesis [4,19-21,23,38-43]. Literatures screening process and the reasons for exclusion were shown in Figure 1.

\section{Study quality assessment}

The methodological quality of all included studies was evaluated using the Newcastle-Ottawa Scale. It mainly included the following three aspects: 1) representativeness of the cohort. Ten studies received four stars, indicating that the representativeness of the cohorts was good [4,19-21,23,38-43]. 2) Comparability. Nine studies received a maximum of two stars [19-21,23,38-41,43], the remaining studies only received one star due to the reason that the exposed (WBCT) and non-exposed (NWBCT) individuals were not matched in the design and/or confounders were not adjusted for in the analysis $[4,42]$. 3) Outcome. Six studies received two stars because of insufficient follow-up time [19-21,39,40,43].

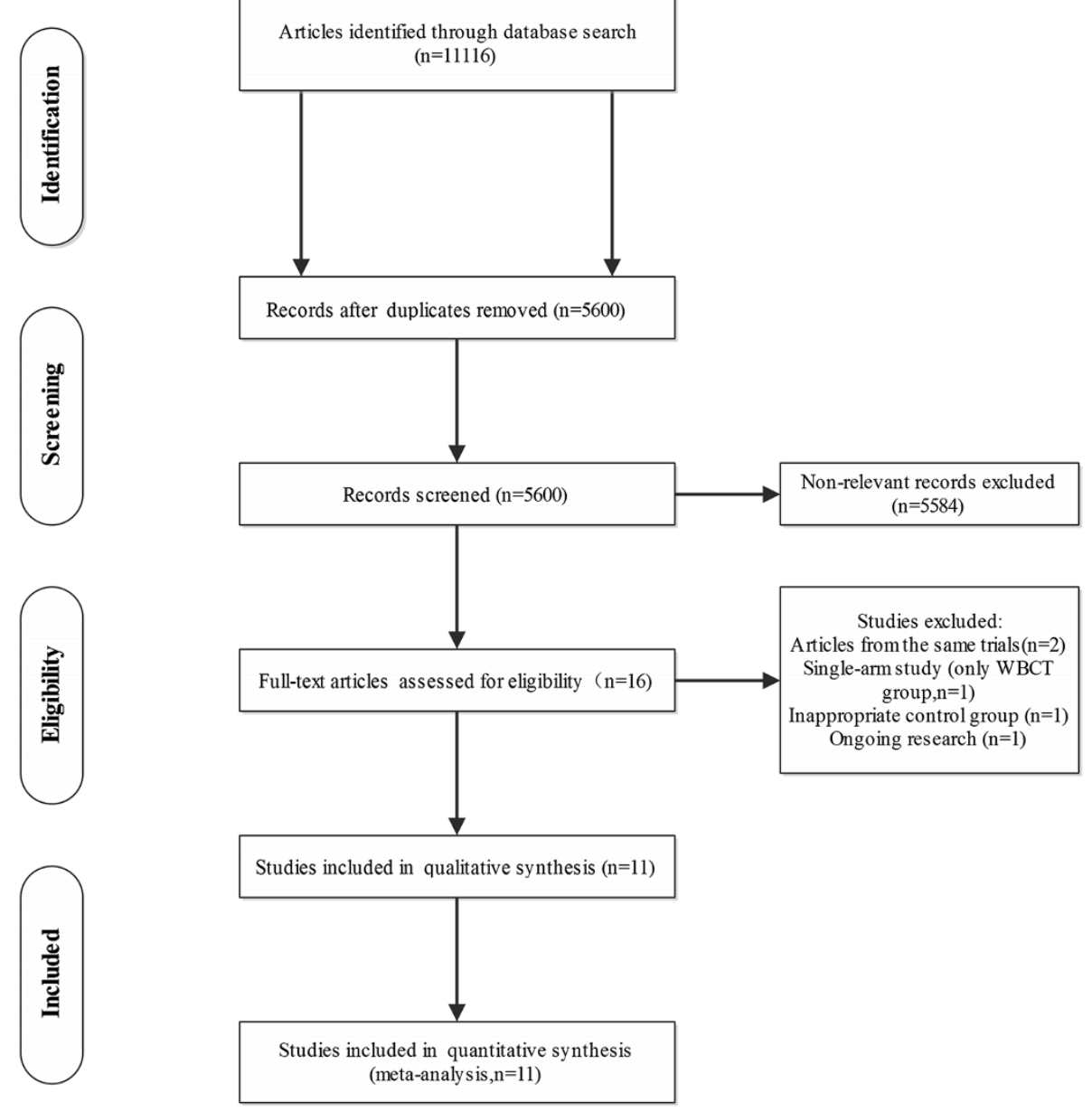

Figure 1 Flow diagram of studies included in this meta-analysis. 
Detailed information are summarized in the Additional file 3.

\section{Study characteristics and meta-analysis Mortality rate}

Ten studies [19-21,23,38-43] reported data on mortality, including four multi-center studies $[19,23,40,41]$ and six single-center studies $[20,21,38,39,42,43]$. The characteristics and results of these studies were summarized in Table 1. Among the included 26210 patients, 14133 patients underwent WBCT. The injury severity was measured using ISS. Patients in the WBCT group had higher ISS than those in the control group in five studies $[19-21,40,41]$. On the contrary, in the study by Wada et al. [23], patients in the NWBCT group had higher ISS than those in the WBCT group. In the study of Hutter et al. [21], 831 patients were included after the introduction of a CT-scan policy. However, nearly $27 \%$ of these patients did not undergo WBCT, probably because they were less severe than other patients. Thus these patients were excluded so as to avoid selection bias $[21,28]$. One of Huber-Wagner's studies [18] was excluded due to the included patients in this study were analyzed in a more recent published study [19]. The study by Bi et al. [42] was excluded because the baseline characteristics of two groups were not reported. We used a random-effects model for the meta-analysis of mortality due to significant heterogeneity among the studies $\left(P<0.00001 ; \mathrm{I}^{2}=82 \%\right)$. The combined OR $(0.66,95 \%$ CI: 0.52 to $0.85 ; P=0.001$, Figure 2) showed significantly lower mortality in patients with WBCT compared to those with NWBCT. The
Egger's test did not show any evidence of publication bias $(P=0.349)$.

\section{Sensitivity analysis}

A sensitivity analysis was conducted to explore potential sources of heterogeneity (Additional file 3 ). In the studies by Hutter et al. and Wada et al. [21,23], the OR was very different from that of the rest of the studies. It was probably because of the sample size of the control group was too small (132 vs 20) in the study by Wada et al. [23]. And 223 patients in the study by Hutter et al. were excluded due to relatively low injury severity [21]. However, heterogeneity still persisted (data not shown) even when we added these patients to the analysis model [21]. Therefore, a sensitivity analysis was performed after excluding the study by Hutter et al. [21]. Our results showed that the association between WBCT and lower mortality did not change and the pooled OR was 0.77 (95\% CI: 0.63 to $0.94 ; P=0.009$ ) with significant heterogeneity $\left(\mathrm{I}^{2}=69 \%\right)$. Similarly, a sensitivity analysis was performed after excluding the study by Wada et al. [23], which revealed that WBCT was still significantly associated with lower mortality rate (OR, $0.72,95 \% \mathrm{CI}: 0.59$ to $0.89 ; P=0.002)$ with significant heterogeneity $\left(\mathrm{I}^{2}=75 \%\right)$. Finally, a further sensitivity analysis was performed after simultaneously excluding these two studies. After pooling the remaining data, the pooled OR was 0.79 (95\% CI: 0.74 to $0.84 ; P<0.00001$ ), which was similar to the above results with non-significant heterogeneity $\left(\mathrm{I}^{2}=0 \%\right.$ ) (Figure 2).

As shown in Table 1, there were significant differences in baseline characteristics between two groups, especially the ISS values. Thus a sensitivity analysis was conducted

Table 1 Characteristics of included studies-mortality

\begin{tabular}{|c|c|c|c|c|c|c|c|c|c|c|c|c|}
\hline \multirow[b]{2}{*}{ Author } & \multirow[b]{2}{*}{ Design } & \multicolumn{2}{|c|}{ Male (\%) } & \multicolumn{2}{|l|}{ Age (year) } & \multicolumn{2}{|c|}{ Cases(n) } & \multicolumn{2}{|l|}{ ISS } & \multicolumn{2}{|c|}{ Mortality } & \multirow{2}{*}{$P$ value } \\
\hline & & A & B & A & B & A & B & A & B & $A$ & B & \\
\hline Sierink et al. [38] & $\operatorname{Re}$ & 70.4 & 71.7 & $43.91(19.67)^{a}$ & $43.63(18.61)^{a}$ & 152 & 152 & $18^{c}$ & $18^{c}$ & $13.2^{\ddagger}$ & $13.2^{\ddagger}$ & 1.00 \\
\hline Huber-Wagner et al. [19] & $\mathrm{Re}$ & 73.0 & 73.2 & $45.2(19.8)^{a}$ & $44.6(20.4)^{a}$ & 9233 & 7486 & $29.7^{\mathrm{a}}$ & $27.7^{\mathrm{a}}$ & $17.4^{\dagger}$ & $21.4^{\dagger}$ & $<0.001$ \\
\hline Weninger et al. [39] & $\operatorname{Re}$ & 72.4 & 73.5 & $43.5(17.2)^{\mathrm{a}}$ & $40.7(18.2)^{a}$ & 185 & 185 & $26.6^{\mathrm{a}}$ & $27.6^{\mathrm{a}}$ & $16.8^{\dagger}$ & $16.2^{\dagger}$ & n.s. \\
\hline Wurmb et al. [20] & $\operatorname{Re}$ & 75 & 77 & $38(3-87)^{b}$ & $38(2-82)^{b}$ & 163 & 155 & $27^{c}$ & $24^{c}$ & $8.5^{\ddagger}$ & $9.0^{\ddagger}$ & NA \\
\hline Hutter et al. [21] & $\operatorname{Re}$ & 75 & 74 & $43.9(19.3)^{a}$ & $43.5(20.7)^{a}$ & 608 & 313 & $28.3^{\mathrm{a}}$ & $26.4^{\mathrm{a}}$ & $7.9^{\dagger}$ & $23.3^{\dagger}$ & $<0.001$ \\
\hline Wada et al. [23] & $\operatorname{Re}$ & 65 & 65 & $40(26-61)^{c}$ & $42(23-64)^{c}$ & 132 & 20 & $34^{c}$ & $41^{c}$ & $18.1^{\ddagger}$ & $80^{\ddagger}$ & $<0.001$ \\
\hline Yeguiayan et al. [41] & Pro & 76.1 & 73.2 & NA & NA & 1696 & 254 & NA & NA & $16.3^{\ddagger}$ & $22^{\ddagger}$ & 0.02 \\
\hline Kimura et al. [40] & $\mathrm{Re}$ & 71 & 70 & $48(47-49)^{d}$ & $53(52-53)^{d}$ & 1858 & 3350 & $26^{a}$ & $23^{a}$ & $24^{\dagger}$ & $28^{\dagger}$ & $<0.001$ \\
\hline Mao et al. [43] & $\mathrm{Re}$ & 75 & 72 & $49.67(17.17)^{a}$ & $45.24(15.51)^{\mathrm{a}}$ & 48 & 75 & $28^{a}$ & $25^{a}$ & $22.9^{\dagger}$ & $22.7^{\dagger}$ & 0.974 \\
\hline Bi et al. [42] & Re & NA & NA & NA & NA & 58 & 87 & NA & NA & $20.7^{\dagger}$ & $39.1^{\dagger}$ & $<0.05$ \\
\hline
\end{tabular}

Re, retrospective; Pro, prospective.

ISS, injury severity score.

${ }^{\dagger}$ Mortality during hospital stay; ${ }^{\ddagger} 30$-day or 28 -day mortality.

ISS, injury severity score.

A, WBCT, whole-body computed tomography.

$B$, NWBCT, no CT or only dedicated CT of one or combined body regions was done (non-whole- body $C T$ ).

NA, not available. n.s., not significant.

${ }^{\mathrm{a}}$ mean (SD); ${ }^{\mathrm{b}}$ median (range); ${ }^{\mathrm{c}}$ median (IQR); ${ }^{\mathrm{d}}$ median (95\% Cl). 


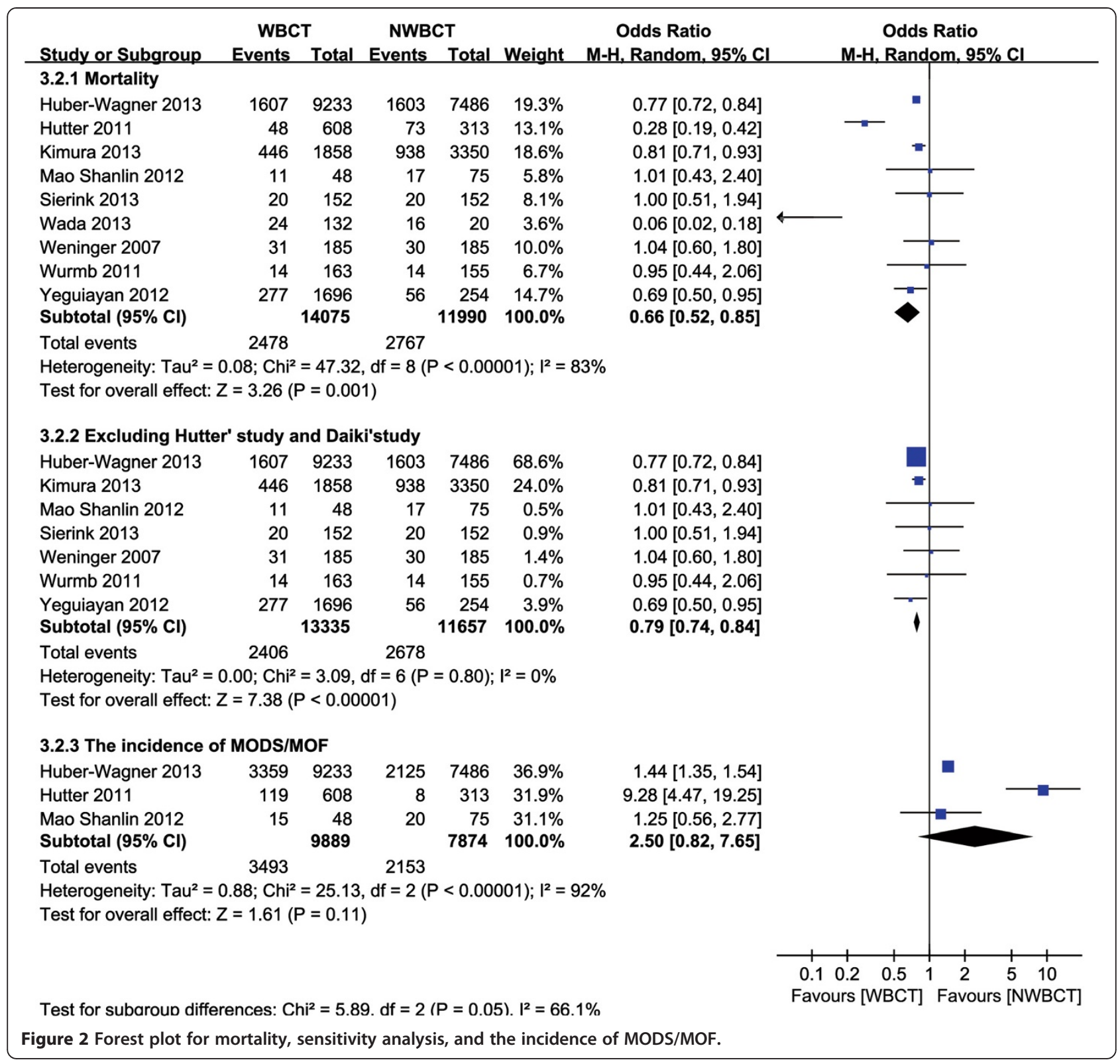

to estimate the robustness of our meta-analysis. Studies were only included in this sensitivity analysis scenario if the study authors adjusted for important confounders, such as ISS values. We obtained adjusted OR and its 95\% CI from five studies for the pooled results $[19,21,38,40,41]$. The pooled OR was 0.54 (95\% CI: 0.37 to $0.79 ; P=0.001)$ with significant heterogeneity $\left(\mathrm{I}^{2}=\right.$ $89.7 \%)$. A sensitivity analysis was also conducted by excluding the study by Hutter et al. [21], in which the adjusted OR was very different from that of the rest of studies. The pooled OR was 0.81 (95\% CI: 0.73 to $0.89 ; P=0.000)$ with insignificant heterogeneity $\left(\mathrm{I}^{2}=34.7 \% ; P=0.204\right)$. Sensitivity analysis was also conducted by adding the study by $\mathrm{Bi}$ et al. [42], which had a high risk of bias. The pooled OR was 0.64 (95\% CI: 0.50 to $0.82 ; P=0.0003)$ which is similar to 0.66 (95\% CI: 0.52 to $0.85 ; P=0.001$ ), indicating that this analysis is reliable.

\section{Secondary outcomes}

Time spent in the emergency department (ED)

Time spent in the ED was reported in six studies (Table 2) $[4,19,21,39,42,43]$. There were no significant differences between the groups in the study by Mao et al. [43], probably because the preparation time for WBCT was too long and the CT room was situated far from the trauma bay. In addition, time spent in the ED was significantly shorter in the WBCT group compared with those in the NWBCT group in the study by Huber- 
Table 2 Characteristics of included studies- ED time

\begin{tabular}{|c|c|c|c|c|c|c|c|}
\hline \multirow[b]{2}{*}{ Reference } & \multicolumn{2}{|c|}{ Number of cases } & \multicolumn{2}{|l|}{ WBCT ED Time } & \multicolumn{2}{|c|}{ NWBCT ED Time } & \multirow[t]{2}{*}{$P$ value } \\
\hline & WBCT & NWBCT & Mean/median & SD/IQR & Mean/median & $\mathrm{SD} / \mathrm{IQR}$ & \\
\hline Huber-Wagneret al. [19] & 9233 & 7486 & $70.69^{\#} \&$ & $41.063^{\#} \&$ & $81.38^{\#} \&$ & $46.53^{\#} \&$ & $<0.05$ \\
\hline Weninger et al. [39] & 185 & 185 & $70^{\#}$ & $17^{\#}$ & $104^{\#}$ & $21^{\#}$ & 0.025 \\
\hline Wurmb et al. [4] & 82 & 79 & $47^{*}$ & $37-59^{*}$ & $82^{*}$ & $66-110^{*}$ & $<0.001$ \\
\hline Hutter et al. [21] & 608 & 313 & $83.5^{\#}$ & $49.2^{\#}$ & $144.7^{\#}$ & $115.8^{\#}$ & $<0.001$ \\
\hline Mao et al. [43] & 48 & 75 & $124.4^{\#}$ & $60.88^{\#}$ & $112.8^{\#}$ & $72.74^{\#}$ & 0.359 \\
\hline Bi et al. [42] & 58 & 87 & $32^{(\mathrm{NR})}$ & $N R$ & $52^{(\mathrm{NR})}$ & NR & NR \\
\hline
\end{tabular}

\#mean/SD; *median/IQR; SD, standard deviation; IQR, interquartile range.

\& personal communication.

WBCT, whole-body computed tomography.

NWBCT, no CT or only dedicated CT of one or combined body regions was done (non-whole- body CT).

$\mathrm{NR}$, not reported.

$E D$, emergency department.

Wagner et al. [19] (Personal communication), Weninger et al. [39], Wurmb et al. [4] and Hutter et al. [21]. The study by $\mathrm{Bi}$ et al. [42] was excluded due to insufficient data. Although heterogeneity was present $(P<0.00001$; $\left.I^{2}=99 \%\right)$, Time spent in the ED was significantly shortened after the introduction of WBCT $(\mathrm{WMD}=-27.58 \mathrm{~min}$; 95\% CI: -43.04 to $-12.12 ; P=0.0005$; Figure 3). The Egger's test demonstrated no evidence of publication bias $(P=0.577)$.

\section{ICU -LOS (days)}

Six studies [19-21,38,39,43] reported data on ICU LOS (Table 3). There was no effect of WBCT on the length of ICU stay in the random-effect model (WMD = 0.95 days, $95 \%$ CI: -0.08 to $1.98, P=0.07$ ) (Figure 4). There was significant heterogeneity between studies $(P<0.00001$; $\left.\mathrm{I}^{2}=92 \%\right)$. The Egger's test demonstrated no evidence of publication bias $(P=0.855)$.

\section{Duration of mechanical ventilation (days)}

Data on the duration of mechanical ventilation were available in five studies $[19,20,38,39,43]$ (Table 3). The results revealed that the WBCT was associated with longer duration of mechanical ventilation in the randomeffect model, the WMD was 0.96 days ( $95 \%$ CI: 0.32 to
1.61, $P=0.003$ ) (Figure 4) with significant heterogeneity $\left(P<0.00001 ; \mathrm{I}^{2}=88 \%\right)$. The Egger's test demonstrated no evidence of publication bias $(P=0.728)$.

\section{Hospital-LOS (days)}

Three studies reported data on the length of hospital stay $[19,38,39]$ (Table 3). There was no effect of WBCT on the length of hospital stay in the fixed-effect model (WMD, 0.56 days, $95 \%$ CI: -0.03 to $1.15 ; P=0.06$ ) (Figure 4 ), with no heterogeneity found between studies $(P=0.43$; $\left.\mathrm{I}^{2}=0 \%\right)$. The Egger's test demonstrated no evidence of publication bias $(P=0.185)$.

\section{The incidence of MODS/ MOF}

Data on the incidence of MODS/MOF were available in three studies $[19,21,43]$ (Table 3). The incidence of MODS/MOF was significantly lower in the NWBCT group compared with the WBCT group in the studies by Huber-Wagner et al. and Hutter et al. [19,21]. Whereas, there was no significant difference between the two groups in the study by Mao et al. [43]. The incidence of MODS/MOF did not differ between the WBCT group and NWBCT group in the random-effect model (OR, 2.50, 95\% CI: $0.82-7.65, \quad P=1.018)$, with significant heterogeneity found between studies $\left(\mathrm{I}^{2}=92 \%\right.$ ) (Figure 2$)$.

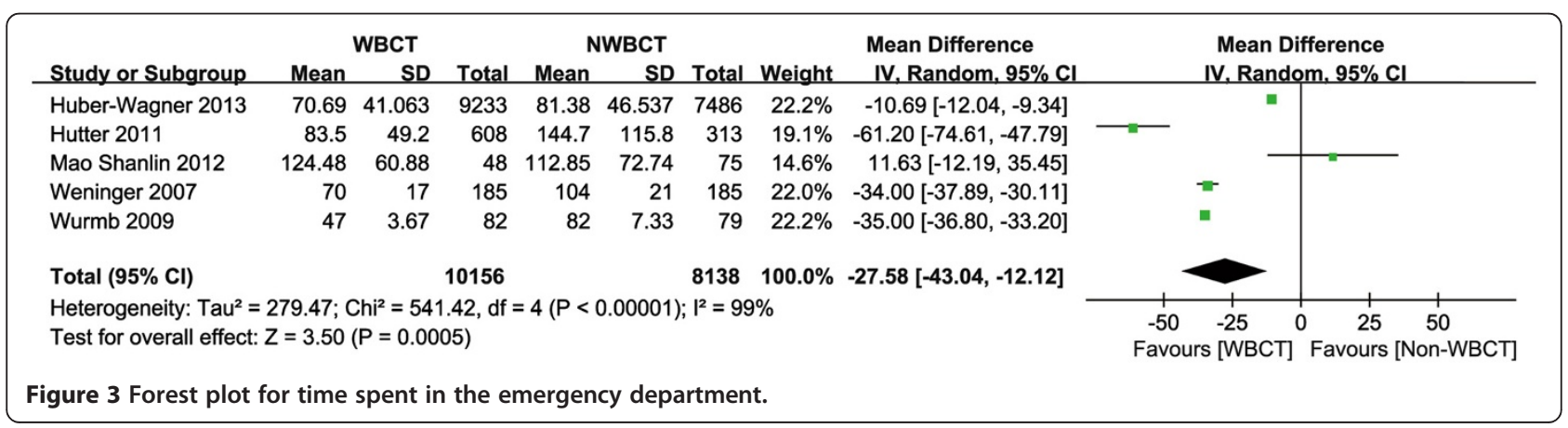


Table 3 Characteristics of included studies-ICU-LOS/Ventilation time/Hospital-LOS

\begin{tabular}{|c|c|c|c|c|c|c|c|c|c|}
\hline \multirow[b]{2}{*}{ Author } & \multicolumn{3}{|l|}{ ICU-LOS } & \multicolumn{3}{|c|}{$\underline{\text { Ventilation time }}$} & \multicolumn{3}{|c|}{ Hospital-LOS } \\
\hline & A & B & $P$ value & Author & A & B & $P$ value & Author & A \\
\hline Huber-Wagner et al [19] & $12.7(14.7)^{*}$ & $11(13.3)^{*}$ & 0.001 & $8.1(12.4)^{*}$ & $7.1(11.1)^{*}$ & 0.001 & $26.7(27.5)^{*}$ & $26(28.4)^{*}$ & 0.001 \\
\hline Sierink et al [38] & $2(0-6)+$ & $1(0-5)+$ & 0.022 & $1(0-3) \dagger$ & $0(0-13)+$ & 0.134 & $9(3-25)+$ & $8.5(1-22.8) \dagger$ & 0.358 \\
\hline Weninger et al [39] & $13.6(14.3)^{*}$ & $16.8(18.7)^{*}$ & 0.042 & $10.9(15.3)^{*}$ & $14.3(15.9)^{*}$ & 0.042 & $29(29.4)^{*}$ & $32.5(33.3)^{*}$ & 0.046 \\
\hline Wurmb et al [20] & $8(2-19) \dagger$ & $5(1-14)+$ & 0.157 & $5(1-15) \dagger$ & $3(1-12)+$ & 0.107 & NA & NA & NA \\
\hline Hutter et al [21] & $16.2(17.3)^{*}$ & $16.2(17)^{*}$ & 0.05 & NA & NA & NA & NA & NA & NA \\
\hline Mao et al [43] & $10.1(9.07)^{*}$ & $13.81(10.3)^{*}$ & 0.044 & $6.85(7.2)^{*}$ & $10.45(10.98)^{*}$ & 0.047 & NA & NA & NA \\
\hline
\end{tabular}

tmedian (IQR ); *mean (SD). SD, standard deviation; IQR, interquartile range.

A, WBCT, whole-body computed tomography.

$B$, NWBCT, no CT or only dedicated CT of one or combined body regions was done (non-whole- body CT). NA, not available.

The study by Hutter et al. [21] was excluded because the OR was very different from that of the rest of the studies. The pooled OR suggested that the incidence of MODS/ MOF was higher in the WBCT group than in the control group (OR, 1.44, 95\% CI: $1.35-1.54 ; P=0.00001$ ), with no heterogeneity $\left(\mathrm{I}^{2}=0\right)$.

\section{GRADE of evidence}

The GRADE of the evidence was summarized in Table 4 .

\section{Discussion}

Our results indicated that the integration of WBCT into the early diagnostic protocol significantly increased the probability of survival in MTPs. We also found that patients in the WBCT group had a significantly shorter ED stay. And there was no effect of WBCT on the length of ICU and hospital stay. To our best knowledge, this is the first meta-analysis of current published trials on the use of WBCT in MTPs.

\begin{tabular}{|c|c|c|c|c|c|c|c|c|c|c|}
\hline \multirow[b]{2}{*}{ Study or Subgroup } & \multicolumn{2}{|r|}{ WBCT } & \multicolumn{3}{|c|}{ NWBCT } & \multirow[b]{2}{*}{ Total } & \multirow[b]{2}{*}{ Weight } & \multirow{2}{*}{$\begin{array}{l}\text { Mean Difference } \\
\text { IV, Random, } 95 \% \mathrm{CI}\end{array}$} & \multirow{2}{*}{\multicolumn{2}{|c|}{$\begin{array}{l}\text { Mean Difference } \\
\text { IV. Random. } 95 \% \mathrm{CI}\end{array}$}} \\
\hline & Mean & SD & Total & Mean & SD & & & & & \\
\hline \multicolumn{11}{|l|}{ 4.1.2 ICU-LOS } \\
\hline Huber-Wagner 2013 & 12.7 & 14.7 & 9233 & 11 & 13.3 & 7486 & $25.1 \%$ & $1.70[1.27,2.13]$ & & - \\
\hline Hutter 2011 & 16.2 & 17.3 & 608 & 16.2 & 17 & 313 & $11.2 \%$ & $0.00[-2.33,2.33]$ & & \multirow{6}{*}{ - } \\
\hline Mao Shanlin 2012 & 10.1 & 9.07 & 48 & 13.81 & 10.3 & 75 & $6.6 \%$ & $-3.71[-7.18,-0.24]$ & & \\
\hline Sierink 2013 & 2 & 1 & 152 & 1 & 0.83 & 152 & $25.9 \%$ & $1.00[0.79,1.21]$ & & \\
\hline Weninger 2007 & 13.6 & 14.3 & 185 & 16.8 & 18.7 & 185 & $6.8 \%$ & $-3.20[-6.59,0.19]$ & & \\
\hline Wurmb 2011 & 8 & 2.83 & 163 & 5 & 2.17 & 155 & $24.4 \%$ & $3.00[2.45,3.55]$ & & \\
\hline Subtotal $(95 \% \mathrm{Cl})$ & & & 10389 & & & 8366 & $100.0 \%$ & $0.95[-0.08,1.98]$ & & \\
\hline \multirow{2}{*}{\multicolumn{11}{|c|}{$\begin{array}{l}\text { Heterogeneity: } \mathrm{Tau}^{2}=1.06 ; \mathrm{Chi}^{2}=63.81, \mathrm{df}=5(P<0.00001) ; \mathrm{I}^{2}=92 \% \\
\text { Test for overall effect: } Z=1.81(P=0.07)\end{array}$}} \\
\hline \multicolumn{6}{|c|}{ Test for overall effect: $Z=1.81(P=0.07)$} & & & & & \\
\hline \multicolumn{11}{|c|}{ 4.1.3 Duration of Mechanical Ventilation (days) } \\
\hline Huber-Wagner 2013 & 6.85 & 7.2 & 48 & 10.45 & 10.98 & 75 & $3.6 \%$ & $-3.60[-6.81,-0.39]$ & & \multirow[b]{2}{*}{ - } \\
\hline Mao Shanlin 2012 & 1 & 0.5 & 152 & 0 & 0.217 & 152 & $33.5 \%$ & $1.00[0.91,1.09]$ & & \\
\hline Sierink 2013 & 10.9 & 15.3 & 185 & 14.3 & 15.9 & 185 & $3.6 \%$ & $-3.40[-6.58,-0.22]$ & & \\
\hline Weninger 2007 & 8.1 & 12.4 & 9233 & 7.1 & 11.1 & 7486 & $30.5 \%$ & $1.00[0.64,1.36]$ & & $=$ \\
\hline Wurmb 2011 & 5 & 2.33 & 163 & 3 & 1.83 & 155 & $28.7 \%$ & $2.00[1.54,2.46]$ & & + \\
\hline Subtotal $(95 \% \mathrm{Cl})$ & & & 9781 & & & 8053 & $100.0 \%$ & $0.96[0.32,1.61]$ & & \\
\hline \multicolumn{11}{|c|}{ Heterogeneity: $\mathrm{Tau}^{2}=0.32 ; \mathrm{Chi}^{2}=33.05, \mathrm{df}=4(\mathrm{P}<0.00001) ; \mathrm{I}^{2}=88 \%$} \\
\hline \multicolumn{11}{|c|}{ Test for overall effect: $Z=2.95(P=0.003)$} \\
\hline \multicolumn{11}{|l|}{ 4.1.4 Hospital-LOS } \\
\hline Huber-Wagner 2013 & 26.7 & 27.5 & 9233 & 26 & 28.4 & 7486 & $47.6 \%$ & $0.70[-0.15,1.55]$ & & - \\
\hline Sierink 2013 & 9 & 3.667 & 152 & 8.5 & 3.633 & 152 & $51.5 \%$ & $0.50[-0.32,1.32]$ & & - \\
\hline Weninger 2007 & 29 & 29.4 & 185 & 32.5 & 33.2 & 185 & $0.8 \%$ & $-3.50[-9.89,2.89]$ & & \\
\hline Subtotal $(95 \% \mathrm{Cl})$ & & & 9570 & & & 7823 & $100.0 \%$ & $0.56[-0.03,1.15]$ & & \\
\hline \multirow{2}{*}{\multicolumn{11}{|c|}{$\begin{array}{l}\text { Heterogeneity: } \mathrm{Tau}^{2}=0.00 ; \mathrm{Chi}^{2}=1.67, \mathrm{df}=2(\mathrm{P}=0.43) ; \mathrm{I}^{2}=0 \% \\
\text { Test for overall effect: } Z=1.87(P=0.06)\end{array}$}} \\
\hline & & & & & & & & & & \\
\hline \multirow{2}{*}{\multicolumn{9}{|c|}{ Test for subaroun differences: $\mathrm{Ch}^{2}=0.96 . \mathrm{df}=2(\mathrm{P}=0.62) . \mathrm{I}^{2}=0 \%$}} & $\begin{array}{ccc}-4 & -2 & 0 \\
\text { Favours [WBCT] }\end{array}$ & $\begin{array}{lcc}0 & 2 & 4 \\
\text { Favours [N }\end{array}$ \\
\hline & & & & & & & & & & \\
\hline ure 4 Forest plot $f$ & ICU-LO & S, ver & tior & tit & $\mathrm{Ho}$ & ital & & & & \\
\hline
\end{tabular}


Table 4 GRADE evidence profile

\begin{tabular}{|c|c|c|c|c|}
\hline \multirow[b]{2}{*}{ Outcomes } & \multicolumn{2}{|l|}{ Illustrative comparative risks* $(95 \% \mathrm{Cl})$} & \multirow[b]{2}{*}{$\begin{array}{l}\text { Relative effect } \\
(95 \% \mathrm{Cl})\end{array}$} & \multirow[b]{2}{*}{ GRADE } \\
\hline & Assumed risk & Corresponding risk & & \\
\hline & NWBCT & WBCT & & \\
\hline \multirow[t]{2}{*}{ Mortality } & 231 per 1000 & 190 per 1000 & OR 0.66 & $\oplus \oplus \ominus \ominus$ low $w^{1,2}$ \\
\hline & & $(180-200)$ & $(0.52-0.85)$ & \\
\hline ED Time & $\begin{array}{l}\text { The mean ED time ranged across control } \\
\text { groups from } 82 \text { to } 144.7 \mathrm{~min}\end{array}$ & $\begin{array}{l}\text { The mean ED time in the intervention groups } \\
\text { was } 27.58 \text { lower ( } 43.04 \text { to } 12.12 \text { lower) }\end{array}$ & NR & $\oplus \oplus \ominus \ominus$ low $w^{1,2,3,4}$ \\
\hline ICU-LOS & $\begin{array}{l}\text { The mean ICU-LOS ranged across control } \\
\text { groups from } 1 \text { to } 16.8 \text { days }\end{array}$ & $\begin{array}{l}\text { The mean ICU-LOS in the intervention groups } \\
\text { was } 0.95 \text { higher ( } 0.08 \text { Lower to } 1.98 \text { higher) }\end{array}$ & $N R$ & $\oplus \ominus \ominus \ominus$ very low $w^{1,2,5}$ \\
\hline Ventilation Time & $\begin{array}{l}\text { The mean duration of mechanical } \\
\text { ventilation ranged across control groups } \\
\text { from } 0 \text { to } 14.3 \text { days }\end{array}$ & $\begin{array}{l}\text { The mean duration of mechanical ventilation } \\
\text { in the intervention groups was } 0.96 \text { higher } \\
(0.32 \text { to } 1.61 \text { higher) }\end{array}$ & NR & $\oplus \Theta \Theta \Theta$ very low $w^{1,2,6}$ \\
\hline Hospital-LOS & $\begin{array}{l}\text { The mean Hospital- LOS ranged across } \\
\text { control groups from } 8.5 \text { to } 32.5 \text { days }\end{array}$ & $\begin{array}{l}\text { The mean Hospital-LOS in the intervention } \\
\text { groups was } 0.56 \text { higher ( } 0.03 \text { Lower to } \\
1.15 \text { higher) }\end{array}$ & NR & $\oplus \ominus \ominus \ominus$ very low $w^{1,2,7}$ \\
\hline \multirow[t]{2}{*}{ MODS/MOF } & 284 per 1000 & 363 per 1000 & OR 1.44 & $\oplus \Theta \Theta \Theta$ very low ${ }^{1,8}$ \\
\hline & & (348 to 379 ) & (1.35 to 1.54$)$ & \\
\hline
\end{tabular}

*The basis for the assumed risk (e.g. the median control group risk across studies) is provided in footnotes. The corresponding risk (and its $95 \%$ confidence interval) is based on the assumed risk in the comparison group and the relative effect of the intervention (and its $95 \% \mathrm{Cl}$ ). $\mathrm{Cl}$ : Confidence interval; OR: Odds ratio. LOS, length of stay; ED time, time spent in the emergency department; NR, not reported.

${ }^{1}$ There were significant differences in baseline characteristics between the two groups (WBCT and NWBCT).

${ }^{2}$ In most of the studies, patients who underwent WBCT had higher levels of injury severity score (ISS).

${ }^{3}$ There was evidence of heterogeneity between studies $\left(\mathrm{Chi}^{2}=541.42, \mathrm{df}=4, \mathrm{P}<0.00001 ; \mathrm{I}^{2}=99 \%\right)$.

${ }^{4}$ The pooled effect size of weighted mean difference $=-27.58 \mathrm{~min} ; 95 \% \mathrm{Cl}-43.04$ to $-12.12 ; \mathrm{p}=0.0005$ )

${ }^{5}$ we found a significant heterogeneity among the studies $\left(\mathrm{Chi}^{2}=63.81, \mathrm{df}=5, \mathrm{P}<0.00001 ; \mathrm{I}^{2}=92 \%\right)$.

${ }^{6}$ The test of heterogeneity showed significant differences in each study $\left(C^{2}{ }^{2}=33.05, d f=4, P<0.00001 ; I^{2}=88 \%\right)$.

${ }^{7}$ The amount of studies (total length of hospital stay was described) is too little.

${ }^{8}$ OR was 1.44 [95\% Cl 1.35-1.54], $\mathrm{p}<0.00001$.

In addition, patients in the WBCT group have a longer duration of mechanic ventilation and a higher incidence of MODS/MOF, as compared with those in the control group. However, it's not yet clear if there is any true cause-and-effect relationship between the application of WBCT and these adverse outcomes. Firstly, this is probably a result of the reduction of the mortality rate in MTPs. Patients that would have died if without WBCT now survive being aware of the whole injury pattern obtained by WBCT early. Therefore, the higher incidence of MODS/MOF in the WBCT group probably because there are more MTPs survivors in the early phase of hospital care. It has been reported that the classic trimodal death distribution of death following injury (the first peak included immediate deaths, the second peak included early hospital death, and The third peak included the late deaths) has been changed and is much more skewed to early hospital death, largely due to better prehospital and intensive care $[44,45]$. Therefore, the biggest challenge is to reduce early hospital mortality. From this perspective, there would seem to be a good rationale for use of WBCT in MTPs to reduce early hospital mortality. Secondly, patients in the WBCT group are more serious (higher ISS values) than those in the NWBCT group which also might account for the higher incidence of MODS/MOF, and longer duration of mechanical ventilation in the WBCT group.

Computed tomography (CT) possesses multiple advantages in MTPs. Firstly, compared with conventional diagnostic approaches, WBCT has higher accuracy especially in the diagnosis of solid organ injuries [39]. Secondly, WBCT can significantly reduce time interval between patient's arrival and the end of life saving procedures, the end of diagnostic procedures, and the beginning of emergency surgery $[4,20,39,46]$. A delay of proper surgical care is associated with higher risk of preventable death in trauma care [20]. Rieger et al. reported that it was possible to detect all injuries through WBCT and the time for diagnostic work-up was shortened by $50 \%$ as a result of the early use of WBCT. Thirdly, patients in the WBCT group have a shorter ED stay in comparison with those in the control group $[4,39,46]$. Hilbert and colleagues found that a new algorithm that integrating multi-slice CT into the early diagnostic protocol can significantly reduce the length of stay in the trauma room [47].

Some researchers hold that it is reasonable to screen MTPs (ISS $\geq 16$ ) with WBCT $[4,23,40,48,49]$. However, how to accurately identify patients who are severely traumatized remains a problem. The conventional approach is based on injury mechanism, clinical symptom, 
and physiological indicators [49]. However, under this triage criteria, almost $30 \%$ of patients were found to have an ISS below 16 (over-triage) [21,49]. Unnecessary CT scanning not only can increase the risk of radiation expose, but also is associated with a substantial economic burden $[26,27]$. Fortunately with the continuous improvement of CT scanning technology, especially after the introduction of iterative reconstruction techniques, the effective dose of WBCT has decreased from 10-20 mSv to 5-10 mSv [19]. And it has been reported that compared to selective CT, WBCT induces no increased radiation dose in favorable situations [50]. Sierink et al. recently reported that although MTPs (ISS $\geqq 16)$ in the WBCT group experienced higher radiation dose in the trauma room, the total radiation dose throughout hospital admission was comparable between groups [25]. In short, the triage rule may need to be reevaluated.

Some limitations of this study deserve to be mentioned. Firstly, all included studies in this meta-analysis are observational, non-randomized studies. However, based on the available data, and the fact that WBCT has significantly speeded up the diagnosis and treatment process and increased the probability of survival in MTPs, we do not feel that randomized controlled trials (RCTs) can change the current evidence, and it is unethical currently. Secondly, there were significant differences in baseline characteristics between groups, especially the ISS values [19-21,23,40,41]. Base-line demographic and clinical characteristics were well matched between the two groups in only two studies $[38,39]$. Moreover, in three studies, the number of patients in the NWBCT and WBCT groups varied significantly which would increase the probability of type I error $[23,40,41]$. Thirdly, we cannot attribute the survival benefits to the application of WBCT directly, as it is well known that trauma mortality has been ameliorated in many developed countries due to the improved trauma management (not only the introduction of WBCT). Hutter et al. [21] and colleagues also reported that both the use and the availability of WBCT were associated with a lower risk of all-cause mortality. This indicates that temporal comparison is also a major confounder. Finally, we cannot rule out other residual confounding factors, such as type of the scanners, scanning methods, indications for WBCT, different inclusion criteria, the location of the scanners or potential publication bias.

\section{Conclusion}

Compared with conventional strategies for early diagnosis of major trauma patients, whole-body computed tomography is associated with a decreased mortality rate and can shorten the time spent in the emergency department.

\section{Additional files}

\section{Additional file 1: PRISMA checklists. \\ Additional file 2: Search strategy.}

Additional file 3: NOS quality assessment scale and the results of sensitivity analysis of mortality rate. NOS, Newcastle-Ottawa Quality Assessment Scale.

\section{Abbreviations}

MTPS: Major trauma patients; CT: Computed tomography; WBCT: Whole-body computed tomography; ICU-LOS: Intensive care unit length of stay; ED: Emergency department; MODS: Multiple organ dysfunction syndrome; MOF: Multiple organ failure; ICU: Intensive care unit; ISS: Injury severity score; WMD: Weighted mean difference; $\mathrm{Cl}$ : Confidence interval; OR: Odds ratio.

\section{Competing interests}

The authors declare that they have no competing interests.

\section{Authors' contributions}

Dr Jiang is guarantor of the paper, taking responsibility for the integrity of the work as a whole, from inception to published article. LBJ MZ YFM conceived and designed the experiments. LBJ SYJ LGY performed the literature search and review. LBJ, LGY, MZ, YFM evaluated the quality of literatures. LBJ LGY extracted relevant data. LBJ SYJ MZ YAX conducted the statistical analysis. LBJ SYJ LGY ZZZ wrote the manuscript. LBJ SYJ YFM LGY ZJZ YAX MZ read and approved the final manuscript.

\section{Acknowledgements}

This work was performed at the Department of Emergency Medicine, Second Affiliated Hospital, Zhejiang University, School of Medicine and Research Institute of Emergency Medicine, Zhejiang University, Hangzhou, China. We thank Xiaojun He, MPH, for providing guidance on the statistical analysis. We also thank all the relevant staff of the EDs for assisting in the implementation of this study.

\section{Funding}

This work was funded by National 12th Five-Year Plan National Technology Support Program (2012BAl11B0).

Received: 6 May 2014 Accepted: 25 August 2014

Published: 2 September 2014

\section{References}

1. Heron M: Deaths: leading causes for 2008. Natl Vital Stat Rep 2012 60(6):1-94

2. Philipp $M O$, Kubin K, Hormann M, Metz VM: Radiological emergency room management with emphasis on multidetector-row CT. Eur J Radiol 2003, 48(1):2-4.

3. Lozano R, Naghavi M, Foreman K, Lim S, Shibuya K, Aboyans V, Abraham J, Adair T, Aggarwal R, Ahn SY, Alvarado M, Anderson HR, Anderson LM, Andrews KG, Atkinson C, Baddour LM, Barker-Collo S, Bartels DH, Bell ML, Benjamin EJ, Bennett D, Bhalla K, Bikbov B, Bin Abdulhak A, Birbeck G, Blyth F, Bolliger I, Boufous S, Bucello C, Burch M, et al:: Global and regional mortality from 235 causes of death for 20 age groups in 1990 and 2010: a systematic analysis for the Global Burden of Disease Study 2010. Lancet 2012, 380(9859):2095-2128.

4. Wurmb TE, Fruhwald P, Hopfner W, Keil T, Kredel M, Brederlau J, Roewer N, Kuhnigk $\mathrm{H}$ : Whole-body multislice computed tomography as the first line diagnostic tool in patients with multiple injuries: the focus on time. J Trauma 2009, 66(3):658-665.

5. Hoyt DB, Bulger EM, Knudson MM, Morris J, lerardi R, Sugerman HJ, Shackford SR, Landercasper J, Winchell RJ, Jurkovich G: Death in the operating room: an analysis of a multi-center experience. J Trauma 1994, 37(3):426-432.

6. Smith W, Williams A, Agudelo J, Shannon M, Morgan S, Stahel P, Moore E: Early predictors of mortality in hemodynamically unstable pelvis fractures. J Orthop Trauma 2007, 21(1):31-37. 
7. Martin M, Oh J, Currier H, Tai N, Beekley A, Eckert M, Holcomb J: An analysis of in-hospital deaths at a modern combat support hospital. J Trauma 2009, 66(4):S51-S60. discussion S60-51.

8. Spahn DR, Bouillon B, Cerny V, Coats TJ, Duranteau J, Fernandez-Mondejar E, Filipescu D, Hunt BJ, Komadina R, Nardi G, Neugebauer E, Ozier Y, Riddez $L$, Schultz A, Vincent $J$, Rossaint R: Management of bleeding and coagulopathy following major trauma: an updated European guideline. Crit Care 2013, 17(2):R76.

9. Postma IL, Beenen LF, Bijlsma TS, Berger FH, Heetveld MJ, Bloemers FW, Goslings JC: Radiological work-up after mass casualty incidents: are ATLS guidelines applicable? Eur Radiol 2014, 24(3):785-791.

10. Gwinnutt C: ATLS approach to trauma management. Acta Anaesthesiol Belg 2005, 56(4):403.

11. Self ML, Blake AM, Whitley M, Nadalo L, Dunn E: The benefit of routine thoracic, abdominal, and pelvic computed tomography to evaluate trauma patients with closed head injuries. Am J Surg 2003, 186(6):609-613. discussion 613-604.

12. Tillou A, Gupta M, Baraff LJ, Schriger DL, Hoffman JR, Hiatt JR, Cryer HM: Is the use of pan-computed tomography for blunt trauma justified? A prospective evaluation. J Trauma 2009, 67(4):779-787.

13. Salim A, Sangthong B, Martin M, Brown C, Plurad D, Demetriades D: Whole body imaging in blunt multisystem trauma patients without obvious signs of injury: results of a prospective study. Arch Surg 2006, 141(5):468-473. discussion 473-465.

14. Watchorn J, Miles R, Moore N: The role of CT angiography in military trauma. Clin Radiol 2013, 68(1):39-46.

15. Langner S, Fleck S, Kirsch M, Petrik M, Hosten N: Whole-body CT trauma imaging with adapted and optimized CT angiography of the craniocervical vessels: do we need an extra screening examination? AJNR Am J Neuroradiol 2008, 29(10):1902-1907.

16. Atluri S, Richard HM 3rd, Shanmuganathan K: Optimizing multidetector $C T$ for visualization of splenic vascular injury. Validation by splenic arteriography in blunt abdominal trauma patients. Emerg Radiol 2011, 18(4):307-312.

17. Okamoto K, Norio H, Kaneko N, Sakamoto T, Kaji T, Okada Y: Use of early-phase dynamic spiral computed tomography for the primary screening of multiple trauma. Am J Emerg Med 2002, 20(6):528-534.

18. Huber-Wagner S, Lefering R, Qvick LM, Korner M, Kay MV, Pfeifer KJ, Reiser M, Mutschler W, Kanz KG: Effect of whole-body CT during trauma resuscitation on survival: a retrospective, multicentre study. Lancet 2009, 373(9673):1455-1461.

19. Huber-Wagner S, Biberthaler P, Haberle S, Wierer M, Dobritz M, Rummeny E, van Griensven M, Kanz KG, Lefering R: Whole-body CT in haemodynamically unstable severely injured patients - a retrospective. multicentre study. PLoS One 2013, 8(7):e68880.

20. Wurmb TE, Quaisser C, Balling H, Kredel M, Muellenbach R, Kenn W, Roewer $\mathrm{N}$, Brederlau J: Whole-body multislice computed tomography (MSCT) improves trauma care in patients requiring surgery after multiple trauma. Emerg Med J 2011, 28(4):300-304.

21. Hutter M, Woltmann A, Hierholzer C, Gartner C, Buhren V, Stengel D: Association between a single-pass whole-body computed tomography policy and survival after blunt major trauma: a retrospective cohort study. Scand J Trauma Resusc Emerg Med 2011, 19:73.

22. Kanz KG, Paul AO, Lefering R, Kay MV, Kreimeier U, Linsenmaier U, Mutschler W, Huber-Wagner S: Trauma management incorporating focused assessment with computed tomography in trauma (FACTT) potential effect on survival. J Trauma Manag Outcomes 2010, 4:4.

23. Wada D, Nakamori Y, Yamakawa K, Yoshikawa Y, Kiguchi T, Ogura H, Kuwagata Y, Shimazu T, Tasaki O, Hamasaki T, Fujimi S: Impact on survival of whole-body computed tomography before emergency bleeding control in patients with severe blunt trauma. Crit Care 2013, 17(4):R178.

24. Ruchholtz S, Lefering R, Paffrath T, Oestern HJ, Neugebauer E, Nast-Kolb D, Pape HC, Bouillon B: Reduction in mortality of severely injured patients in Germany. Dtsch Arztebl Int 2008, 105(13):225-231.

25. Sierink JC, Saltzherr TP, Wirtz MR, Streekstra GJ, Beenen LF, Goslings JC Radiation exposure before and after the introductionof a dedicated total-body CT protocol multitrauma patients. Emerg Radiol 2013, 20(6):507-512.

26. Loewenhardt B, Buhl M, Gries A, Greim CA, Hellinger A, Hessmann M, Rathjen T, Reinert M, Manke C, Bernhard M: Radiation exposure in whole-body computed tomography of multiple trauma patients: bearing devices and patient positioning. Injury 2012, 43(1):67-72.
27. Snyder GE: Whole-body imaging in blunt multisystem trauma patients who were never examined. Ann Emerg Med 2008, 52(2):101-103.

28. Stengel D, Frank M, Matthes G, Schmucker U, Seifert J, Mutze S, Wich M, Hanson B, Giannoudis PV, Ekkernkamp A: Primary pan-computed tomography for blunt multiple trauma: can the whole be better than its parts? Injury 2009, 40(Suppl 4):S36-S46.

29. Linsenmaier U, Krotz M, Hauser H, Rock C, Rieger J, Bohndorf K, Pfeifer KJ, Reiser M: Whole-body computed tomography in polytrauma: techniques and management. Eur Radiol 2002, 12(7):1728-1740.

30. Sierink JC, Saltzherr TP, Reitsma JB, Van Delden OM, Luitse JS, Goslings JC: Systematic review and meta-analysis of immediate total-body computed tomography compared with selective radiological imaging of injured patients. Br J Surg 2012, 99(Suppl 1):52-58.

31. Healy DA, Hegarty A, Feeley I, Clarke-Moloney M, Grace PA, Walsh SR: Systematic review and meta-analysis of routine total body CT compared with selective CT in trauma patients. Emerg Med J 2013, 31(2):101-108.

32. Moher D, Liberati A, Tetzlaff J, Altman DG: Preferred reporting items for systematic reviews and meta-analyses: the PRISMA statement. BMJ 2009, 339:b2535.

33. Hozo SP, Djulbegovic B, Hozo I: Estimating the mean and variance from the median, range, and the size of a sample. BMC Med Res Methodo/ 2005, 5:13.

34. DerSimonian R, Laird N: Meta-analysis in clinical trials. Contr Clin Trials 1986, 7(3):177-188.

35. Egger M, Davey Smith G, Schneider M, Minder C: Bias in meta-analysis detected by a simple, graphical test. BMJ 1997, 315(7109):629-634.

36. Balshem $H$, Helfand M, Schunemann HJ, Oxman AD, Kunz R, Brozek J, Vist GE, Falck-Ytter Y, Meerpohl J, Norris S, Guyatt GH: GRADE guidelines: 3. Rating the quality of evidence. J Clin Epidemiol 2011, 64(4):401-406.

37. Guyatt GH, Oxman AD, Schunemann HJ, Tugwell P, Knottnerus A: GRADE guidelines: a new series of articles in the Journal of Clinical Epidemiology. J Clin Epidemiol 2011, 64(4):380-382.

38. Sierink JC, Saltzherr TP, Beenen LF, Russchen MJ, Luitse JS, Dijkgraaf MG, Goslings JC: A case-matched series of immediate total-body CT scanning versus the standard radiological work-up in trauma patients. World J Surg 2013, 38(4):795-802

39. Weninger $P$, Mauritz W, Fridrich P, Spitaler R, Figl M, Kern B, Hertz H: Emergency room management of patients with blunt major trauma: evaluation of the multislice computed tomography protocol exemplified by an urban trauma center. J Trauma 2007, 62(3):584-591.

40. Kimura A, Tanaka N: Whole-body computed tomography is associated with decreased mortality in blunt trauma patients with moderate-tosevere consciousness disturbance: a multicenter, retrospective study. J Trauma Acute Care Surg 2013, 75(2):202-206.

41. Yeguiayan JM, Yap A, Freysz M, Garrigue D, Jacquot C, Martin C, Binquet C, Riou B, Bonithon-Kopp C: Impact of whole-body computed tomography on mortality and surgical management of severe blunt trauma. Crit Care 2012, 16(3):R101.

42. Zhongfu B: The value of emergent spiral CT of multiple body regions in severe mutiple trauma patients. Modern Medicine 2011, 39(4):459-460.

43. Mao Shanlin X, Xinfa XY, Hongfei W, Lijun L: The value of whole-body CT in severe traffic trauma patients during the early resuscitation phase. Chinese J Trauma 2012, 28(3):269-271.

44. Evans JA, van Wessem KJ, McDougall D, Lee KA, Lyons T, Balogh ZJ: Epidemiology of traumatic deaths: comprehensive population-based assessment. World J Surg 2010, 34(1):158-163.

45. Sauaia A, Moore FA, Moore EE, Moser KS, Brennan R, Read RA, Pons PT: Epidemiology of trauma deaths: a reassessment. J Trauma 1995 38(2):185-193.

46. Wurmb T, Balling $H$, Fruhwald $P$, Keil T, Kredel M, Meffert R, Roewer N, Brederlau J: Polytrauma management in a period of change: time analysis of new strategies for emergency room treatment. Unfallchirurg 2009, 112(4):390-399.

47. Hilbert P, Zur Nieden K, Hofmann GO, Hoeller I, Koch R, Stuttmann R: New aspects in the emergency room management of critically injured patients: a multi-slice CT-oriented care algorithm. Injury 2007, 38(5):552-558.

48. Rieger M, Sparr H, Esterhammer R, Fink C, Bale R, Czermak B, Jaschke W: Modern CT diagnosis of acute thoracic and abdominal trauma. Anaesthesist 2002, 51(10):835-842.

49. Wurmb TE, Fruhwald P, Hopfner W, Roewer N, Brederlau J: Whole-body multislice computed tomography as the primary and sole diagnostic 
tool in patients with blunt trauma: searching for its appropriate indication. Am J Emerg Med 2007, 25(9):1057-1062.

50. Wedegartner U, Lorenzen M, Nagel HD, Weber C, Adam G: Diagnostic imaging in polytrauma: comparison of radiation exposure from whole-body MSCT and conventional radiography with organ-specific CT. RöFo 2004, 176(7):1039-1044.

doi:10.1186/s13049-014-0054-2

Cite this article as: Jiang et al:: Comparison of whole-body computed tomography vs selective radiological imaging on outcomes in major trauma patients: a meta-analysis. Scandinavian Journal of Trauma Resuscitation and Emergency Medicine 2014 22:54.

\section{Submit your next manuscript to BioMed Central and take full advantage of:}

- Convenient online submission

- Thorough peer review

- No space constraints or color figure charges

- Immediate publication on acceptance

- Inclusion in PubMed, CAS, Scopus and Google Scholar

- Research which is freely available for redistribution 